University of Nebraska - Lincoln

DigitalCommons@University of Nebraska - Lincoln

USDA National Wildlife Research Center - Staff Publications
U.S. Department of Agriculture: Animal and Plant Health Inspection Service

2011

\title{
Landscape Genetics of Fishers (Martes pennanti) in the Northeast: Dispersal Barriers and Historical Influences
}

\author{
Paul Hapeman \\ University of Florida, fishers@ufl.edu \\ Emily K. Latch \\ University of Wisconsin-Milwaukee \\ Jennifer A. Fike \\ Purdue University \\ Olin E. Rhodes Jr. \\ Purdue University, rhodes@srel.uga.edu \\ C. William Kilpatrick \\ University of Vermont
}

Follow this and additional works at: https://digitalcommons.unl.edu/icwdm_usdanwrc

Part of the Life Sciences Commons

\begin{abstract}
Hapeman, Paul; Latch, Emily K.; Fike, Jennifer A.; Rhodes, Olin E. Jr.; and Kilpatrick, C. William, "Landscape Genetics of Fishers (Martes pennanti) in the Northeast: Dispersal Barriers and Historical Influences" (2011). USDA National Wildlife Research Center - Staff Publications. 1359.

https://digitalcommons.unl.edu/icwdm_usdanwrc/1359
\end{abstract}

This Article is brought to you for free and open access by the U.S. Department of Agriculture: Animal and Plant Health Inspection Service at DigitalCommons@University of Nebraska - Lincoln. It has been accepted for inclusion in USDA National Wildlife Research Center - Staff Publications by an authorized administrator of DigitalCommons@University of Nebraska - Lincoln. 


\title{
Landscape Genetics of Fishers (Martes pennanti) in the Northeast: Dispersal Barriers and Historical Influences
}

\author{
Paul Hapeman, Emily K. Latch, Jennifer A. Fike, Olin E. Rhodes, and C. William Kilpatrick
}

From the Department of Biology, University of Florida, Gainesville, FL 326 II (Hapeman); the Department of Biological Sciences, University of Wisconsin-Milwaukee, Milwaukee, WI (Latch); the Department of Forestry and Natural Resources, Purdue University, West Lafayette, IN (Fike and Rhodes); and the Department of Biology, University of Vermont, Burlington, VT (Kilpatrick). Olin E. Rhodes is now at USDA-APHIS Wildlife Services, National Wildlife Research Center, 4I0I LaPorte Avenue, Fort Collins, CO 8052I.

Address correspondence to P. Hapeman at the address above, or e-mail: fishers@ufl.edu.

\begin{abstract}
Habitat fragmentation and overtrapping are thought to have resulted in severe population declines for fisher (Martes pennanti) across the northeastern United States, and by the end of the 1930s only 3 remnant populations remained. Subsequent trapping cessation, extensive reintroduction programs, and natural recolonization have helped fishers to reclaim much of their historical range. The degree to which these processes have impacted genetic structure in this species, however, remains unknown. We used 11 microsatellites from tissue samples $(n=432)$ of fishers to characterize contemporary population structure in light of historical population structure and thus to determine the relative influence of anthropogenic disturbances and natural landscape features in shaping genetic structure of the contemporary population. Our results indicated that 3 well-differentiated contemporary populations are present that correspond well with what would be expected based on their reported history. A course barrier to dispersal appears in the western portion of the study area associated with several lakes including Lake George and Great Sacandaga Lake. Large-scale reintroduction efforts and natural recolonizations have largely had predictable impacts on population structure. An important exception is the substantial impact of the reintroduction of fishers to Vermont.
\end{abstract}

Key words: landscape genetics, Martes pennanti, reintroduction, substructure, spatial

The history of fishers (Martes pennanti) in the northeastern United States is fairly typical of many North American species. Fishers were trapped extensively during the period from the 1800 s to the early 1900 s, during which time habitat was being lost and fragmented at a rapid rate (Powell 1993; Powell and Zielinski 1994). Habitat fragmentation and overtrapping are thought to have resulted in severe population declines across the northeast, and by the end of the 1930 s, only 3 remnant populations remained. These 3 populations were located in habitat fragments in the White Mountains of New Hampshire, the Moosehead Plateau of Maine and the Adirondack Mountains of New York (Brander and Books 1973; Powell 1993). Allozyme data indicate that these refugial populations exhibited modest genetic differentiation (Williams et al. 2000).

Closed trapping seasons and a series of reintroductions carried out between 1959 and 1991 helped to restore fishers to much of their historical range in the northeast (Figure 1). The reintroduction history of fishers is well documented and includes 124 fishers moved from Maine to Vermont over an 8-year period (1959-1967; Berg 1982; Brown and Parsons 1983; Trombulak and Royar 2001), 43 fishers relocated from the Adirondacks to the Catskill region of southern New York between 1976 and 1979 (Brown and Parsons 1983; Wallace and Henry 1985), and 4 fishers from Vermont, and 30 fishers from New Hampshire relocated to northwestern Connecticut between 1989 and 1991 (Williams et al. 2000). Natural immigration is thought to have occurred in combination with reintroductions and together have allowed fishers to regain much of their historical distribution in the northeast.

Although the recovery of fishers in the northeastern United States appears to be successful from a demographic perspective, the genetic structure of contemporary fisher populations may have changed considerably. A long and convoluted history of population declines due to habitat fragmentation and overtrapping, reintroductions of unknown success, and natural range expansions may have 


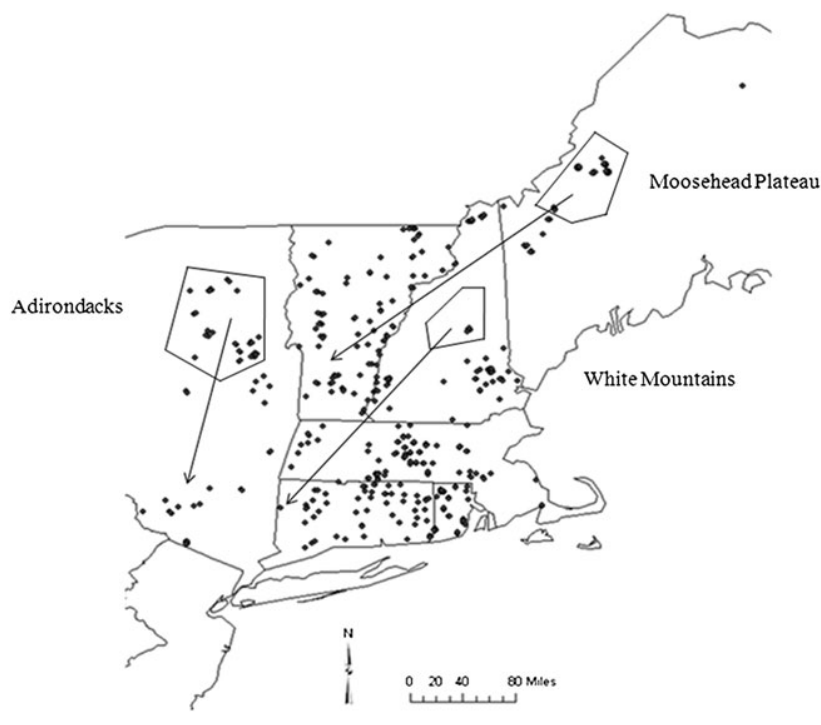

Figure I. Locations of samples $(n=432)$ of fishers across the study area. Approximate locations of 3 historic refugia (Adirondacks, NY; White Mountains, NH; Moosehead Plateau, ME) reported by Brander and Books (1973) are represented as polygons and dark outlines. Arrows indicate origin and direction of documented reintroductions in the study area. Specific areas were not used for Vermont as fishers were introduced throughout the state.

disrupted historical population structure. However, it is unclear to what degree these processes have impacted fishers.

If human-mediated relocations and disturbances have affected patterns of gene flow in fishers, then the contemporary population structure should deviate considerably from that previously defined (Brander and Books 1973; Powell 1993; Williams et al. 2000) and anthropogenic factors may be paramount in shaping the genetic structure of fishers. Alternatively, if the natural population structure has been maintained even in the face of large-scale movements and disturbances, then contemporary populations may be structured in much the same way as historical populations and natural features of the landscape may drive patterns of gene flow in fishers. Our goal is to characterize contemporary population structure in fishers and determine whether current fisher populations in the northeast exhibit patterns of genetic structure expected based on their reported history. We also characterize the relative influence of natural landscape features and anthropogenic disturbances in shaping genetic structure of fishers in this region.

\section{Materials and Methods}

We obtained tissue samples during carcass collections from fishers killed during trapping seasons between 1998 and 2002. Samples were collected and processed with the cooperation of state agencies in New York $(n=82)$, Massachusetts $(n=79)$, Vermont $(n=91)$, and New
Hampshire $(n=59)$. Samples of fishers from Connecticut $(n=47)$ and Rhode Island $(n=35)$ were obtained from roadkills, and samples from Maine $(n=55)$ were collected by trappers during the annual trapping season. Each sample's collection site was reported as the nearest geographic feature (mountain, lake) or nearest town, which was converted to coordinates in decimal degrees (Figure 1). Based on samples of known localities versus reported localities, the maximum error of any reported location is estimated at $8 \mathrm{~km}$.

We extracted DNA using a standard phenol-chloroform procedure (Blin and Stafford 1976) or a modified ammonium acetate protocol (Latch et al. 2006). Eleven microsatellite loci were chosen for this study from a suite of loci developed and screened in mustelids (RIO04, RIO06, RIO12, and RIO20, Beheler et al. 2004, 2005; Mvis-002 and Mvis-072, Fleming et al. 1999; Lut-604, Dallas and Piertney 1998; Ma-1 and Ma-19, Davis and Strobeck 1998; Ggu-101 and Ggu-216, Duffy et al. 1998). Microsatellites were amplified via polymerase chain reaction (PCR) in $10 \mu \mathrm{l}$ amplification reactions with 5-10 ng genomic DNA, 1-4 pmol forward and reverse primers, $0.2 \mathrm{mM}$ each dNTP, and 0.75 units Taq DNA polymerase (Eppendorf) in $1 \times$ reaction buffer $(50 \mathrm{mM} \mathrm{KCl}, 10 \mathrm{mM}$ Tris-HCl, pH 8.3, $1.5 \mathrm{mM}$ $\mathrm{Mg}(\mathrm{OAc})_{2}$. Microsatellites were amplified with the following thermocycler conditions: a 2-min initial denaturation step at $95^{\circ} \mathrm{C}, 30$ cycles of $30 \mathrm{~s}$ at $95^{\circ} \mathrm{C}, 30 \mathrm{~s}$ at the annealing temperature (Table 1), and 30 seconds at $72^{\circ} \mathrm{C}$, followed by a final extension for $5 \mathrm{~min}$ at $72{ }^{\circ} \mathrm{C}$, and $60^{\circ} \mathrm{C}$ for $45 \mathrm{~min}$. PCR products were stored at $4{ }^{\circ} \mathrm{C}$ for up to $72 \mathrm{~h}$ prior to electrophoresis. Products from amplified loci were combined into 4 gel sets based on size of the PCR product and fluorescent label color (NED, HEX, 6-FAM) with each gel set containing 2-3 loci. Combined PCR products were added to $0.2 \mu \mathrm{l} 400 \mathrm{HD}$ ROX internal lane standard and electrophoresed through a $5 \%$ polyacrylamide gel on an ABI 377 DNA sequencer. Allele sizes were determined for each locus using GENESCAN 3.1 and GENOTYPER 2.5 software (ABI).

A number of different methods were employed to ensure the quality of the microsatellite genotype data. First, we developed a pooled set of 3-4 known alleles for each locus, spanning the full range of allele sizes. The pooled sets were combined into gel sets as above and incorporated within sample sets as allelic standards in 1 of every 12 lanes on each gel. Genotyping error can occur if allelic categories are not consistently and accurately defined, and the use of allelic standards allowed us to detect and correct for any microvariability within or among gels in the migration of alleles relative to the internal lane standard. Second, a random set of 88 individuals were rescored at all loci to verify genotypes. Genotyping errors were assessed by comparing genotypes from 2 independent estimations of fragment sizes. Third, ambiguous genotypes, those with low signal intensity $(<100$ as determined by GENOTYPER 2.5 software), were reelectrophoresed or reamplified to confirm the genotype. Fourth, unreliable samples were discarded prior to analysis. Samples were deemed unreliable if they 
Table I Conditions for PCRs for 11 microsatellites

\begin{tabular}{lllcllc}
\hline Locus & $\begin{array}{l}\text { Anneal } \\
\left({ }^{\circ} \mathrm{C}\right)\end{array}$ & $\begin{array}{l}\text { Template } \\
(\mathrm{ng})\end{array}$ & $\begin{array}{l}\text { Primers } \\
(\mathrm{pmol})\end{array}$ & $\begin{array}{l}\mathrm{Mg} \\
(\mathrm{mM})\end{array}$ & $\begin{array}{l}\text { Size } \\
\text { range }\end{array}$ & $\begin{array}{l}\text { No. of } \\
\text { alleles }\end{array}$ \\
\hline Ggu-216 & 56 & 15 & 7.5 & 2.25 & $162-182$ & 9 \\
Ggu-101 & 56 & 10 & 7.5 & 3 & $143-155$ & 7 \\
Ma-19 $^{1}$ & 56 & 15 & 7.5 & 2.25 & $199-215$ & 7 \\
Ma-1 & 56 & 15 & 7.5 & 2.25 & $199-207$ & 5 \\
Lut-604 $^{a}$ & 54.3 & 10 & 7.5 & 3 & $121-141$ & 9 \\
Mvis-002 $^{a}$ & 56 & 10 & 7.5 & 3 & $200-216$ & 5 \\
Mvis-072 $^{a}$ & 54.3 & 10 & 7.5 & 3 & $275-285$ & 6 \\
RIO16 & 55 & 10 & 5 & 1.5 & $260-276$ & 5 \\
RIO07 & 60 & 10 & 5 & 3 & $122-130$ & 5 \\
RIO12 & 55 & 10 & 10 & 1.5 & $191-216$ & 6 \\
RIO20 & 54.8 & 10 & 5 & 3 & $252-254$ & 2 \\
\hline
\end{tabular}

All reactions were performed in $10 \mu \mathrm{l}$ reaction volumes and included $200 \mu \mathrm{M}$ each dNTP and $1 \mathrm{U}$ Taq DNA polymerase.

${ }^{a}$ HotstartTaq.

successfully amplified at fewer than $25 \%$ of the loci, despite multiple amplification and DNA extraction attempts.

\section{Analytical Methods}

The number of genetically distinct clusters (subpopulations), $K$, was inferred from the total data set $\left(n_{\text {loci }}=11 ; n_{\text {samples }}=\right.$ 432) using STRUCTURE 2.2 (Falush et al. 2003). We ran models in STRUCTURE with a burn-in of 500000 iterations and run length of 1000000 iterations assuming admixture and correlated allele frequencies among clusters. The admixture parameter alpha $(\alpha)$ was allowed to vary and was inferred separately for each population when asymmetric admixture was suspected among genetic clusters. The allele frequency parameter lambda $(\lambda)$ was set by first estimating lambda for the data set using a model without admixture (Pritchard and Wen 2003), then set to a constant value for all subsequent analyses. The burn-in and run lengths were considered sufficient when model parameters, particularly the admixture parameter $(\alpha)$, achieved "stability" at the end of the burn-in period (Pritchard and Wen 2003). The method of Evanno et al. (2005) was used as the best estimate of the number of genetic clusters $(K)$ in the data set using the ad hoc statistic $\Delta K$. Populations inferred from STRUCTURE within the total data set were further examined for substructuring using additional runs.

We also assessed population structure using the programs GENELAND version 3.14 (Guillot, Estoup, et al. 2005; Guillot, Mortier, and Estoup 2005) and TESS 2.1 (François et al. 2006). Both programs use spatial information from samples to estimate the number of clusters. The biggest difference between the 2 programs is GENELAND that can only model population structure without admixture, whereas TESS can model population structure with or without admixture.

In GENELAND, the spatial-D model was used to infer the number of subpopulations (clusters), $K$. Initial runs allowed $K$ to vary under the following conditions; 50000 stored iterations of the Markov chain, maximum rate of
Poisson process set equal to the number of samples, minimum population number set to 1 and maximum to 8 , and the number of nuclei in the Poisson-Voronoi tessellation set at 3 times the sample size (Guillot, Estoup, et al. 2005; Guillot, Mortier, and Estoup 2005). The delta.coord parameter (noise parameter associated with spatial locations) was set to 0.05 , which corresponds to $\sim 3.5$ $\mathrm{km}$ ). Longer runs of the Markov chain (200 000 stored iterations) and alternative values for the uncertainty parameter ( 0 and 0.1 , which correspond to 0 and $\sim 7 \mathrm{~km})$ did not significantly impact either the number of populations inferred or the posterior probability of membership for individual samples. Once $K$ was inferred, a final run was completed to establish population boundaries. These boundaries then were correlated with landscape features using geographic maps to identify potential dispersal barriers. Clusters identified in GENELAND were used in all subsequent population analyses, including assignment tests and within population measures of genetic diversity.

We modeled population structure in TESS assuming admixture using 500000 iterations of the Markov chain and a 50000 iteration burn-in. The following parameters were varied to find the model with the highest average likelihood over 10 runs; interaction parameter (0.1-0.6), number of assumed populations (2-8), and allele frequency model (1-3) with the remaining parameters set at default values. The model with the highest average likelihood over 10 runs was taken to be the number of clusters in the data. The visual extent of the clusters across the study area is included in the output from TESS.

Frequency-based assignment tests were conducted between each pair of populations using the leave-one-out method in the program GenAlEx 6.2 (Peakall and Smouse 2006). The exclusion method of Cornuet et al. (1999) was carried out for each population using the program GENECLASS2 (10000 simulated individuals in each population and a rejection criteria of 0.05; Piry et al. 2004).

Frantz et al. (2009) found that isolation by distance (IBD) can confound the results from Bayesian clustering algorithms. In addition to employing multiple clustering algorithms to our data set to identify the most parsimonious underlying patterns, we used Mantel tests to identify the presence of IBD across the study area and within each inferred population. For the Mantel tests, pairwise genetic (Nei 1972) and geographic distances were calculated among all samples. The correlation between matrices of genetic distance (Nei 1972) and Euclidean distance between all pairs of samples was assessed by permutation in GenAlEx 6.2 (Peakall and Smouse 2006).

Two geographic barriers inferred from GENELAND were assessed using partial Mantel tests (Smouse et al. 1986) in GenAlEx. The first barrier occurs between the West and Central clusters and consists of Lake Champlain south to Lake George and Great Sacandaga Lake. The second barrier consists of the Connecticut River that separates the east and central clusters. The barrier distance matrix included values of 1 if 2 individuals were found on opposite sites of a putative barrier and 0 if they were on the same side. 
Significance was assessed using 10000 permutations of the data in XLSTAT 2009.4.02 (Addinsoft).

We identified putative migrants as those individuals with higher probabilities of membership (from the runs with fixed $K$ ) in clusters other than the one in which they were sampled and visualized relative to proposed cluster boundaries from GENELAND. Ongoing gene flow was assessed by estimating migration rates (within last 2 generations) among inferred populations using BayesAss version 1.3 (Wilson and Rannala 2003).

We calculated observed and expected heterozygosities and mean numbers of alleles in each of the inferred populations using GDA version 1.1 (Lewis and Zaykin 2001). Allelic richness for each inferred population was calculated in HP-Rare version 1.0 (Kalinowski 2005). Deviations from Hardy-Weinberg and linkage equilibrium were examined using exact tests in the program GENEPOP version 3.4 (Raymond and Rousset 1995). Results were adjusted for multiple comparisons using a sequential Bonferroni correction (Rice 1989). Each inferred population was further examined for deviation from Hardy-Weinberg equilibrium using estimates of $F_{\text {IS }}$ calculated in GDA. Genetic differentiation among inferred populations was examined using F-statistics (Weir and Cockerham 1984) in GDA version 1.1 (Lewis and Zaykin 2001). The significance of all $F$-statistics was determined by bootstrapping over loci using 1000 replicates.

\section{Results}

All 3 Bayesian clustering algorithms yielded concordant results, inferring 3 genetically distinct populations (Figures $2-4)$. Over repeated runs in STRUCTURE, the highest loglikelihood was found at $K=4$; however, it did not represent a notable improvement over $K=3$ as indicated by the $\Delta K$ statistic. $K=3$ also seemed to better represent the data, as it both clustered samples into more geographically meaningful groups (Figure 2) and increased the mean assignment probabilities for all clusters. Both GENELAND and TESS revealed 4 clusters; however, both had a single inferred population with no samples assigned to them. These "ghost" populations have been recognized as artifacts of rarely visited states in the Markov chain, and it has been recommended that these be ignored (Guillot, Estoup, et al. 2005; Chen et al. 2007).

Based on boundaries identified by GENELAND, clusters were labeled as follows: "West" including samples from the Adirondack and Catskill Mountains of New York $(n=52)$; "Central" including samples from Maine, Vermont, northern New Hampshire, eastern counties in New York (Warren, Washington, and Saratoga), and western and central Massachusetts $(n=179)$; and "East" with samples from central and southern New Hampshire, eastern Massachusetts, Connecticut, and Rhode Island ( $n=201$; Figure 3).

Potential dispersal barriers were identified on topographic maps by identifying landscape features in the vicinity of the boundaries identified by GENELAND. In northern

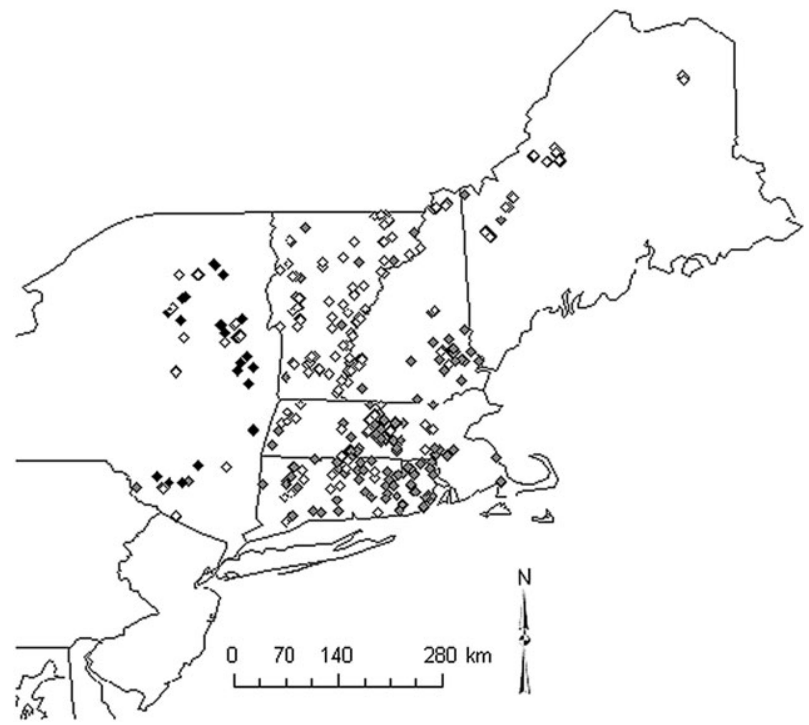

Figure 2. Membership of samples in 3 genetic clusters from the program STRUCTURE. Clusters are identified as follows; West $=$ black, Central $=$ white, East $=$ gray .

New Hampshire, the White Mountains separate the Central from the East cluster (Figure 5a). In central New England, the Connecticut River appears to be a barrier to dispersal for much of its length between the East and Central clusters (Figure 5b). In New York, a series of lakes beginning with Lake Champlain and ending near Lake George and the Great Sacandaga Lake demarcate the boundary between the West and Central clusters (Figure 5c).

All individuals were assigned to their population of origin in the comparison between West and Central clusters,

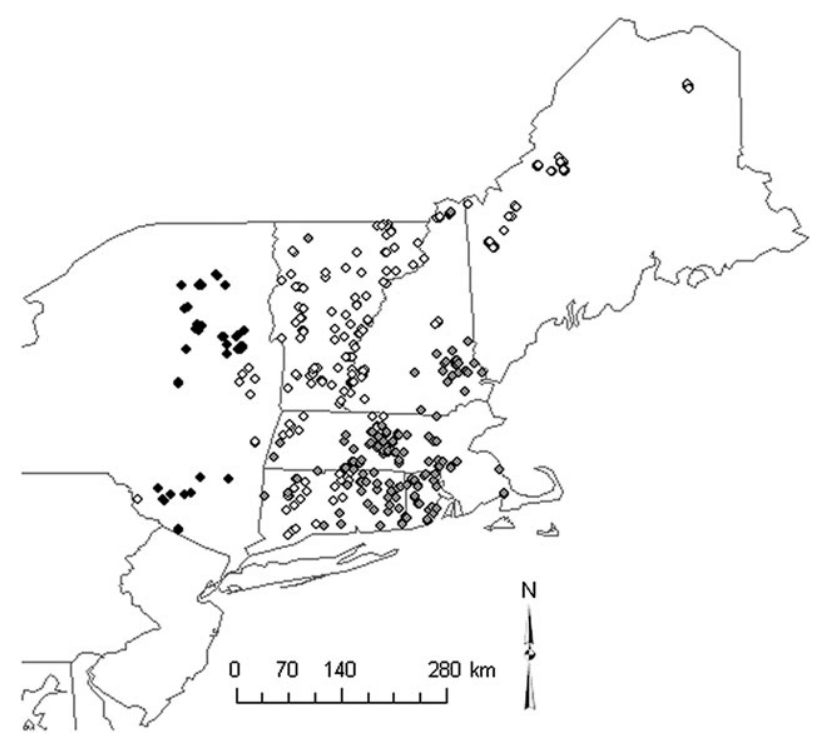

Figure 3. Membership of samples in 3 genetic clusters from the program GENELAND. Clusters are identified as follows; West $=$ black, Central $=$ white, East $=$ gray. 


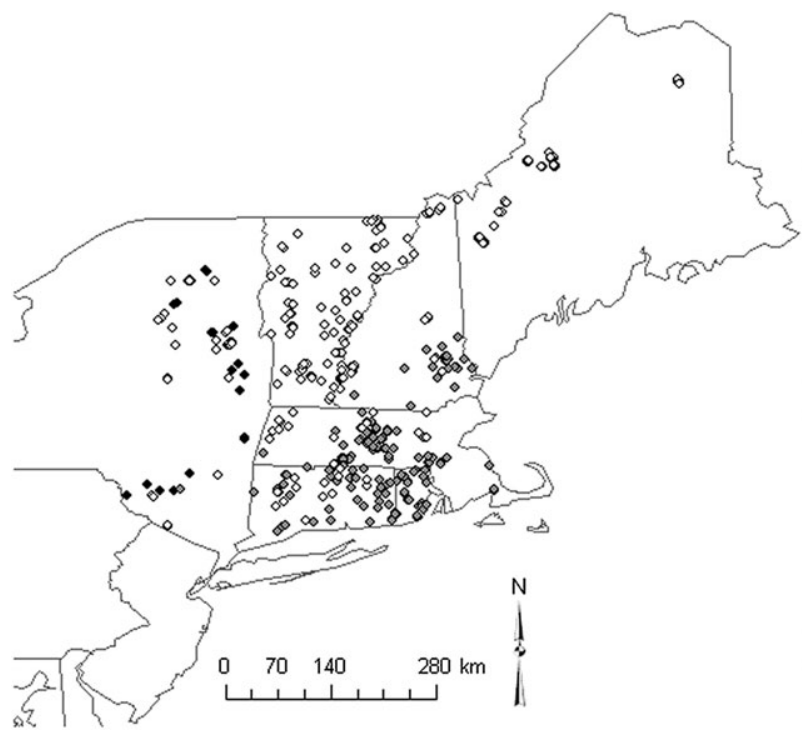

Figure 4. Membership of samples in 3 genetic clusters from the program TESS. Clusters are identified as follows; West $=$ black, Central $=$ white, East $=$ gray.

indicating that the barrier to dispersal between these populations is strong. The barrier between Central and East clusters is not quite as strong; $83 \%$ of individuals were assigned to the population in which they were sampled. No individuals from the inferred clusters defined by GENELAND were excluded from their assigned population using the simulation procedure of Paetkau et al. (2004), suggesting that source populations for all samples were present in the data set.

Significant correlations between genetic and geographic distances were found in the entire data set and in most inferred clusters $(r=0.187, P=0.001 ; r$ East $=0.042$, $P=0.17$; $r$ Central $=0.062, P=0.02$; $r$ West $=0.178, P=$ $0.01)$. The correlation between genetic and geographic distance in the Central-West subpopulations $(r=0.267, P<$ $0.0001)$ decreased significantly once the effect of barrier was removed $(r=0.079, P<0.0001)$, whereas the correlation between genetic distance and the barrier remained high $(r=$ 0.253, $P<0.0001)$. In the Central-East comparison, the correlation between genetic and geographic distance was low $(r=0.037, P<0.001)$ and decreased once the effect of the barrier was removed $(r=0.023, P<0.019)$. The correlation between genetic distance and the barrier in the central-east subpopulations was very low once the effect of geographic distance was removed $(P=0.017, P<0.097)$. These results suggest that although IBD is acting to limit gene flow in fishers, barriers to dispersal also are influencing gene flow, particularly between the Central and West subpopulations.

Several loci in the inferred clusters did not conform to expected patterns of Hardy-Weinberg equilibrium (West cluster [Lut-604, Ma-1, RIO12, and Mvis-002], Central cluster [Mvis-002], and East cluster [RIO12, Ma-19]). Small but significantly positive $F_{\text {IS }}$ values (Central 0.045; East
0.049; West 0.096) were observed in the Central and East clusters (Table 2) that may indicate additional substructuring that went undetected by clustering algorithms. Relatively little difference was observed in mean number of alleles or allelic richness among these 3 populations (Table 2). All inferred populations were genetically differentiated from one another (East-Central $=0.049,95 \%$ confidence interval [CI 0.031-0.069; East-West $=0.143,95 \%$ CI 0.096-0.200; Central-West $=0.079,95 \%$ CI $0.064-0.103)$.

Eight samples were identified as possible migrants based on the population boundaries identified by GENELAND. Migrants had higher posterior probabilities of membership in populations other than those from which they were sampled (Figure 6), and all 8 samples were assigned to East population, although they were sampled in Central $(n=6)$ or West clusters $(n=2)$. The estimates of recent migration rates (last 2 generations) from BayesAss indicated that recent migration rates were generally low (0.0032-0.0751) and that the populations are composed primarily of nonimmigrants individuals (Table 3).

\section{Discussion}

Habitat fragmentation and overtrapping of fishers over a century ago have left lasting impacts on the genetic structure of fisher populations. Large-scale reintroduction efforts and natural recolonizations have been important for the overall demographic recovery of the species and have left distinct genetic signatures that are detectable even today. However, gene flow across northeastern North America remains primarily influenced by natural features of the landscape rather than anthropogenic activities.

Today, the overall structure of fisher populations corresponds well with what would be expected based on their reported history. Fishers are currently structured into 3 subpopulations that largely correspond to the 3 refugial populations identified in remnant habitat fragments at the end of the 1930s; namely, the Adirondacks of New York, the White Mountains of New Hampshire, and the Moosehead Plateau of Maine (Brander and Books 1973; Williams et al. 2000).

Our results are similar to those of Williams et al. (2000), who found significant differences in allele frequencies among

Table 2 Measures of genetic diversity in inferred clusters of fishers

\begin{tabular}{lllllll}
\hline Cluster & $n$ & $H_{\mathrm{o}}$ & $H_{\mathrm{e}}$ & $\bar{A}$ & $A_{\mathrm{r}}$ & $F_{\mathrm{IS}}$ \\
\hline Central & 179 & 0.57 & 0.59 & 5.09 & 4.57 & $0.045^{*}$ \\
East & 201 & 0.49 & 0.52 & 5.18 & 4.33 & $0.049^{*}$ \\
West & 52 & 0.51 & 0.56 & 4.55 & 4.50 & 0.096 \\
\hline
\end{tabular}

Genetic variation was quantified using observed heterozygosity $\left(H_{\mathrm{o}}\right)$, expected heterozygosity $\left(H_{\mathrm{e}}\right)$, mean number of alleles across 11 loci $(\bar{A})$ in GDA version 1.1 (Lewis and Zaykin 2001). Allelic richness $\left(A_{\mathrm{r}}\right)$ was calculated using the rarefaction method in HP-Rare version 1.0 (Kalinowski 2005). Estimates of $F_{\mathrm{IS}}$ for each population were calculated in GDA version 1.1 (Lewis and Zaykin 2001). Values significantly different from zero for $F_{\text {IS }}$ are indicated by an asterisk $(\alpha=0.05)$. 

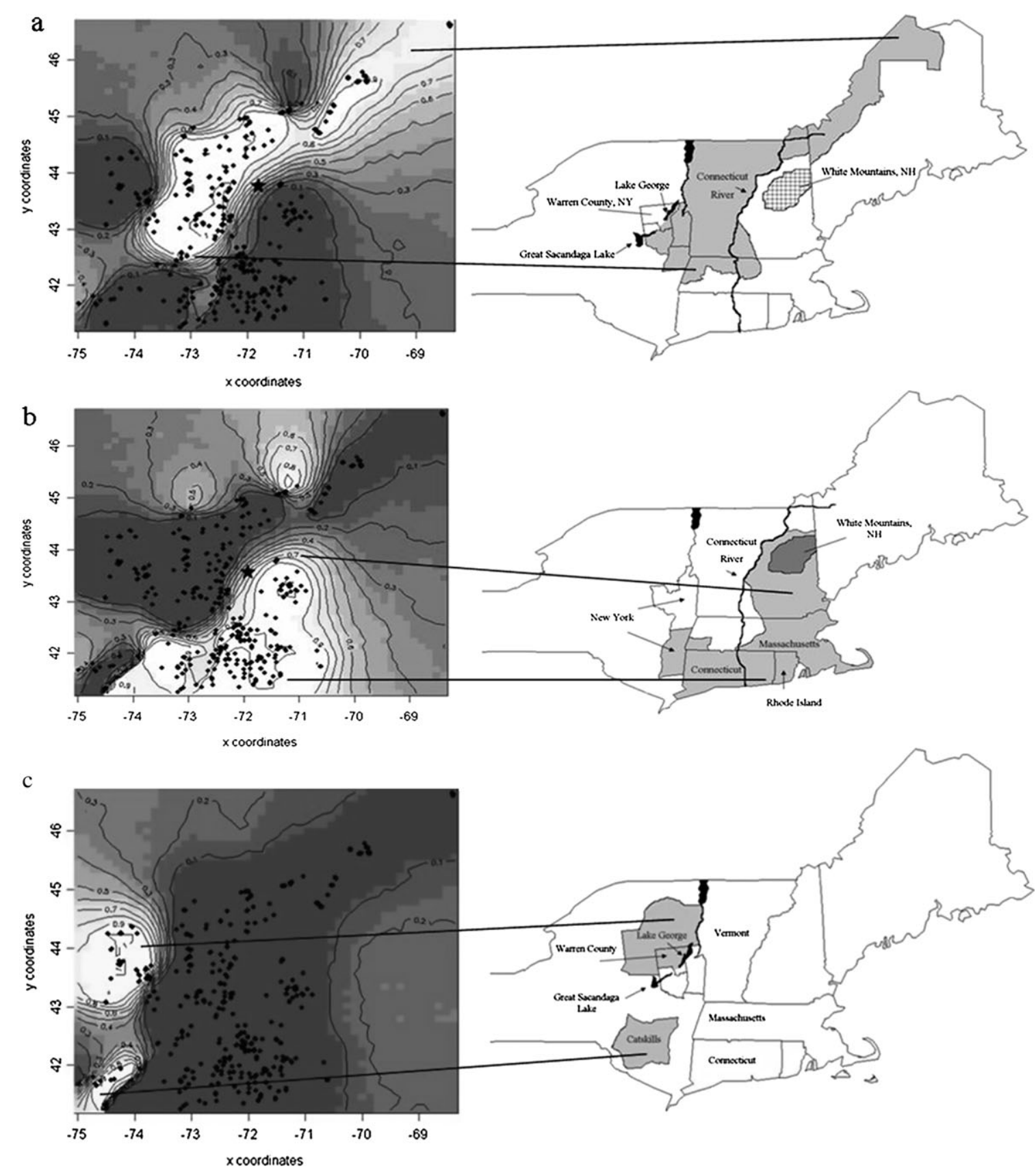

Figure 5. Maps showing posterior probabilities of cluster membership and location of genetic discontinuities for each of the 3 inferred clusters, (a) Central, (b) East, (c) West, as determined by GENELAND version 3.14 (Guillot, Estoup, et al. 2005). Lighter shading indicates higher probability of cluster membership. Geographic coordinates were used to determine the geographic extent of each cluster and to correlate discontinuities with landscape features (on right). Star symbol on Tessellation maps ( $a, b$, left side) indicates location of Connecticut River.

these same 3 refugial populations. By including more highly variable markers and more samples from a wider geographic extent, we were able to determine that these refugial populations are not only genetically distinct at their cores but retain distinctiveness even where the subpopulations meet. We were also able to delineate the boundaries of these refugial populations and investigate the genetic influences of more contemporary anthropogenic disturbances.
A deficiency of heterozygotes within the inferred subpopulations indicates that additional substructure may be present. This is perhaps not surprising, given that reintroductions have occurred within some of the inferred subpopulations and thus allele frequencies may not have yet reached equilibrium. This is further supported by our clustering results, where each genetic cluster contained fishers from both reintroduced populations and their 


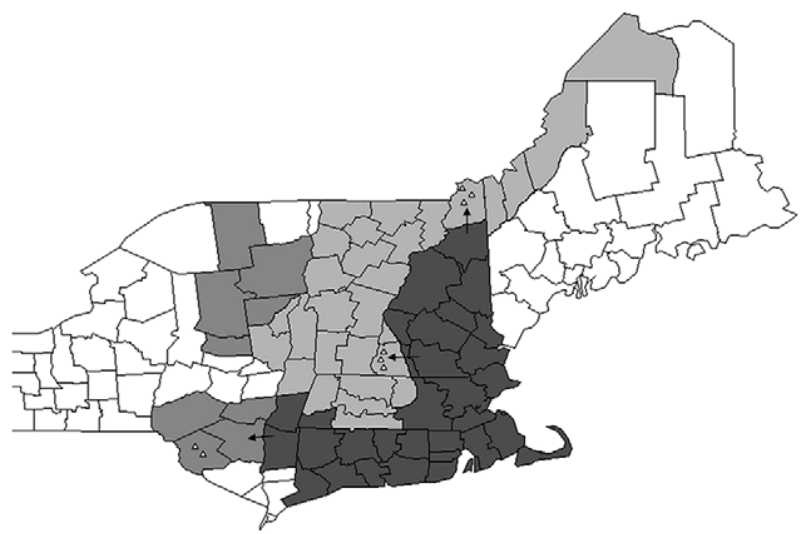

Figure 6. Map of northeastern United States showing the 3 clusters of fishers (dark gray $=$ East, medium gray $=$ West, and light gray $=$ Central) as identified based on the posterior probabilities of membership calculated in GENELAND.

Unshaded areas were not sampled. Potential migrants $(n=8)$ were found within the total sample of fishers $(n=432)$ from the GENELAND program. Migrants were identified based on their geographic location relative to proposed cluster boundaries and their posterior probabilities of membership. Arrows indicate the most likely direction of migration.

sources. For example, fishers from Vermont and Maine were grouped into a single subpopulation (Central), a pattern that likely reflects the reintroduction of fishers from Maine to Vermont between 1959 and 1967. Natural recolonizations have likely had a similar effect on allele frequencies as newly colonized or recently expanded populations may not have reached equilibrium. However, our analyses focused on the broad-scale patterns of genetic structure and thus were able to identify discrete subpopulations across the region.

Table 3 Migration rates among 3 inferred clusters from GENELAND version 1.05 (Guillot, Estoup, et al. 2005) using the program BayesAss version 1.3 (Wilson and Rannala 2003)

\begin{tabular}{clcc}
\hline & Into & & \\
\cline { 2 - 4 } & West & Central & East \\
\hline From & & & \\
West & $*$ & $0.0032)$ & $(0.0046)$ \\
Lower & $*$ & 0.0001 & 0.004 \\
Upper & $*$ & $*$ & 0.0115 \\
Central & $(0.0603)$ & $*$ & $(0.0366)$ \\
Lower & 0.0057 & $*$ & 0.0072 \\
Upper & 0.1474 & $(0.0751)$ & $* .0757$ \\
East & $(0.0321)$ & 0.0319 & $*$ \\
Lower & 0.004 & 0.1211 & $*$ \\
Upper & 0.0815 & & \\
\hline
\end{tabular}

Migration rates (in parentheses) were estimated in BayesAss using the default input parameters. Migration rates reflect the proportion of the individuals within a cluster identified as migrants from another sampled cluster over the past few generations. Lower and upper values represent bounds of $95 \%$ CIs for estimates of migration rates.
Barriers to gene flow for fishers exist in the northeast, which might be surprising given the high dispersal potential of fishers in this region (Roy 1991; York 1996). All clustering methods yielded highly concordant results, despite differences in the way each method considers admixture. Methods that considered admixture indicated that the level of admixture among the inferred subpopulations was very low, and migration rates were similarly low. We found very few migrants into neighboring populations, and migrants and individuals of mixed ancestry were not concentrated in the vicinity of a barrier.

The barriers identified in our study correspond to distinct features of the landscape that are impacting fisher movements. The boundary between the West and Central populations extends from Lake Champlain south through Warren County to Great Sacandaga Lake and Lake George (Figure 3c) and was well supported by our data. All individuals in these 2 subpopulations were correctly assigned, no migrants were detected in our sample, and our estimate of migration rate was very low. Partial Mantel tests provided additional support for the inferred barrier, suggesting that the barrier was a far better predictor of genetic variation than geographic distance. The location of this barrier is also consistent with a break in mitochondrial DNA identified previously (Hapeman 2006). The presence of these lakes may be acting to slow the mixing of the West and Central populations by funneling fisher dispersal through a narrow corridor between Lake George and Great Sacandaga Lake. Within this narrow east-west corridor, there is a large highway (I-87) and a river (Stony Creek) that run north-south and may be further restricting fisher dispersal.

Between the Central and East subpopulations, geographic distance appears to be the major factor driving genetic differentiation. The correlation between genetic and geographic distance remained significant even after the effect of an inferred barrier was removed. In cases where IBD is the primary factor driving allele frequency distributions across the landscape, it can be difficult to detect barriers to dispersal that might be acting as secondary factors limiting dispersal (Frantz et al. 2009). However, the congruence of our clustering algorithms suggested the presence of a barrier between the Central and East subpopulations. The break in allele frequencies between these 2 subpopulations corresponds to the location of the Connecticut River. Previous work has shown that large rivers are substantial barriers to the movements of fishers (Coulter 1966; Kelly 1977; Wisely et al. 2004), and the land adjacent to the Connecticut River contains many farms and nonforested areas, which may be further restricting dispersal as fishers avoid open spaces in favor of forested habitat with extensive canopy cover (Coulter 1966; Kelly 1977; Powell 1993; Raine 1983; Arthur et al. 1989). However, our data indicate that the Connecticut River is likely a very weak barrier to fisher gene flow. Genetic differentiation between the Central and East subpopulations was lower than that between other subpopulation pairs, the number of misassignments was higher, migration rates were higher, and the 
number of immigrants detected was higher. Additionally, partial Mantel tests showed a very weak correlation between genetic distance and barriers once the effect of geographic distance was removed.

The boundary between the Central and East subpopulations becomes even less clear north of the White Mountains. Although it is possible that the White Mountains are a barrier to fisher dispersal, a large number of migrants identified north of the White Mountains suggest the exact mechanisms influencing fisher dispersal in this region may be more complex. One alternative is that the Connecticut River, which is much smaller to the north than it is to the south of the mountains, is an even less restrictive barrier to fisher dispersal north of the White Mountains. A second possibility is that fishers from northern New Hampshire represent an unsampled subpopulation to the north. Carr et al. (2007) found that fishers sampled in lower Ontario originated from northern New York, and it is possible that our northern New Hampshire samples are difficult to assign because they are connected to populations outside the study area. This seems unlikely given the fact that none of the individuals were excluded from the sampled populations; however, additional sampling at a broader scale would permit more detailed investigation of putative barriers in this region.

Genetic signatures from reintroductions are evident throughout the region. Reintroductions were undertaken from Maine to Vermont, from the Adirondacks to the Catskills in New York, and from New Hampshire to Connecticut. In all 3 cases, the source and reintroduced populations were characterized as belonging to the same genetic subpopulation. For example, fishers from Vermont are genetically very similar to those from their source population in Maine. It appears that Vermont fishers moved south and recolonized western Massachusetts where they contact fishers associated with the East subpopulation in western Connecticut. These western Connecticut fishers are in turn most related to their source population in New Hampshire. Reintroductions have left identifiable signatures in a number of other species (Leberg and Ellsworth 1999; Larson et al. 2002; DeYoung et al. 2003; Latch and Rhodes 2005; Williams and Scribner 2010), and it is clear that they have contributed to the patterns of genetic structure in contemporary fisher populations.

Our data show that the population structure of fishers at the end of the 1930s, when overhunting and habitat loss had reduced fisher populations to their lowest point, has been maintained in contemporary fisher populations. Extensive reintroductions undertaken to facilitate demographic recovery of the species have left distinct genetic signatures on the region, most notably the reintroduction of fishers to Vermont. However, because most reintroductions used source populations from nearby locations, the overall pattern of genetic structure in the region has remained largely unchanged. Our data indicate that gene flow among contemporary fisher subpopulations is maintained by a combination of natural landscape features, and it appears that hydrologic features may be primarily responsible for limiting gene flow in fishers. These findings show that both population history and contemporary barriers to gene flow are working in concert to shape the evolutionary trajectory of populations.

\section{Funding}

University of Vermont, Vermont Genetics Network; Rhodes laboratory at Purdue University.

\section{Acknowledgments}

Many people deserve thanks for contributing time, effort, and samples to this project including Mark Brown, Scott Smith and the New York Department of Environmental Conservation, Charlie Brown and the Rhode Island Division of Fish and Wildlife, Eric Orff, Will Staats and the New Hampshire Fish and Game Department, Kim Royar and the Vermont Fish and Wildlife Department, Paul Rego and employees at Connecticut Department of Environmental Protection, Chrissy Henner, Tony Gola and the Massachusetts Division of Fish and Wildlife, Wally Jakubas and the Maine Department of Inland Fisheries and Wildlife, Greg Gallant, Rick Crowe, Tom Stevens, Eugene Worster, and Harry Seekins, and Dwight Pennell. Jonathan Pritchard provided helpful feedback during the drafting process.

\section{References}

Arthur SM, Krohn WB, Gilbert JR. 1989. Home range characteristics of adult fishers. J Wldl Manage. 53:674-679.

Beheler AS, Fike JA, Murfitt LM, Rhodes OE Jr., Serfass TS. 2004. Development of polymorphic microsatellite loci for North American river otters (Lontra canadensis) and amplification in related mustelids. Mol Ecol Notes. 4:56-58.

Beheler AS, Fike JA, Dharmarajan G, Rhodes OE Jr., Serfass TL. 2005. Ten new polymorphic microsatellite loci for North American river otters (Lontra canadensis) and their utility in related mustelids. Mol Ecol Notes. 5:602-604.

Berg WE. 1982. Reintroduction of fisher, pine marten, and river otter. In: Sanderson G, editor. Midwest Furbearer Management. Proceedings of Symposia $43^{\text {rd }}$ Midwest Fish and Wildlife Conference. Bloomington (IL): North Central Section of the Wildlife Society. p. 159-173.

Blin N, Stafford DW. 1976. A general method for isolating high molecular weight DNA from eukaryotes. Nucleic Acids Res. 2:2303-2308.

Brander RB, Books DJ. 1973. Return of the fisher. Nat His. 82:52-57.

Brown MK, Parsons GR. 1983. Movement of a male fisher in southern NewYork. NY Fish and Game J. 30:114-115.

Carr D, Bowman J, Wilson PJ. 2007. Density-dependent dispersal suggests a genetic measure of habitat suitability. Oikos. 116:629-635.

Chen C, Durand E, Forbes F, François O. 2007. Bayesian clustering algorithms ascertaining population structure: a new computer program and a comparative study. Mol Ecol Notes. 7:747-752.

Coulter MW. 1966. Ecology and management of fishers in Maine $\mathrm{PhD}$ dissertation]. [Syracuse (NY)]: Syracuse University p. 183

Dallas JF, Piertney SB. 1998. Microsatellite primers for the Eurasian otter. Mol Ecol. 7:1248-1251.

Davis CS, Strobeck C. 1998. Isolation, variability, and cross-species amplification of polymorphic microsatellite loci in the family Mustelidae. Mol Ecol. 7:1771-1788. 
DeYoung RW, Demarais S, Honeycutt RL, et al. 2003. Genetic consequences of white-tailed deer (Odocoileus virginianus) restoration in Mississippi. Mol Ecol. 12:3237-3252.

Duffy AJ, Landa A, O’Connell M, Stratton C, Wright JM. 1998. Four polymorphic microsatellites in wolverine, Gulo gulo. Anim Genet. 29:63-72.

Evanno G, Regnaut S, Goudet J. 2005. Detecting the number of clusters of individuals using the software structure: a simulation study. Mol Ecol. 14:2611-2620.

Cornuet JM, Piry S, Luikart G, Estoup A, Solignac M. 1999. New methods employing multilocus genotypes to select or exclude populations as origins of individuals. Genetics. 153:1989-2000.

Falush D, Stephens M, Pritchard JK. 2003. Inference of population structure using multilocus genotype data: linked loci and correlated allele frequencies. Genetics. 164:1567-1587.

Fleming MA, Ostrander EA, Cook JA. 1999. Microsatellite markers for American mink (Mustela vison) and ermine (Mustela erminea). Mol Ecol. 8:1352-1354.

François O, Ancelet S, Guillot G. 2006. Bayesian clustering using hidden markov random fields in spatial population genetics. Genetics. 174:805-816.

Frantz AC, Cellina S, Krier A, Scley L, Burke T. 2009. Using spatial Bayesian methods to determine the genetic structure of a continuously distributed population: clusters or isolation by distance? J Appl Ecol. 46:493-505.

Guillot G, Estoup A, Mortier F, Cosson JF. 2005. A spatial statistical model for landscape genetics. Genetics. 170:1261-1280.

Guillot G, Mortier F, Estoup A. 2005. Geneland: a program for landscape genetics. Mol Ecol Notes. 5:712-715.

Hapeman PH. 2006. The populations genetics of fishers (Martes pennanti) across northeastern North America [PhD dissertation]. [Burlington (VT)]: University of Vermont p. 264

Kalinowski ST. 2005. HP-Rare 1.0: a computer program for performing rarefaction on measures of allelic richness. Mol Ecol Notes. 5:187-189.

Kelly GM. 1977. Fisher (Martes pennanti) biology in the White Mountain National Forest and adjacent areas [PhD Dissertation]. [Amherst (MA)]: University of Massachusetts p. 178

Latch EK, Harveson LA, King JS, Hobson MD, Rhodes OE Jr. 2006. Assessing hybridization in wildlife populations using genetic markers: a case study in wild turkeys. J Wildl Manage. 70:485-492.

Latch EK, Rhodes OE Jr. 2005. The effects of gene flow and population isolation on the genetic structure of reintroduced wild turkey populations: are genetic signatures of source populations retained? Conserv Genet. 6:981-997.

Larson S, Jameson R, Bodkin J, Staedler M, Bentzen P. 2002. Microsatellite DNA and mitochondrial variation in remnant and translocated sea otter (Enhydra lutris) populations. J Mammal. 83:893-906.

Leberg PL, Ellsworth DL. 1999. Further evaluation of the genetic consequences of translocations on southeastern white-tailed deer populations. J Wldl Manage. 63:327-334.

Lewis PO, Zaykin D. 2001. Genetic Data Analysis (GDA) version 1.1: computer program for the analysis of allelic data. [updated $2002 \mathrm{Jan} 7$; cited 2008 Oct 16]. Available from: http://hydrodictyon.eeb.uconn.edu/people/ plewis/software.php

Nei M. 1972. Genetic distance between populations. Am Nat. 106:283-292.
Paetkau D, Slade R, Burdens M, Estoup A. 2004. Genetic assignment methods of the direct, real-time estimation of migration rate: a simulationbased exploration of accuracy and power. Mol Ecol. 13:55-65.

Peakall R, Smouse PE. 2006. GENALEX 6: genetic analysis in Excel. Population genetic software for teaching and research. Mol Ecol Notes. 6:288-295.

Piry S, Alapetite A, Cornuet J-M, Paetkau D, Baudouin L, Estoup A. 2004. GENECLASS2: a software for genetic assignment and first generation migrant detection. J Hered. 95:536-539.

Powell RA. 1993. The fisher: life history, ecology, and behavior. 2nd ed. Minneapolis (MN): University of Minnesota Press.

Powell RA, Zielinski WJ. 1994. Fisher. In: Ruggiero L, Aubry K, Buskirk S, Lyon L, Zielinski W, editors. The scientific basis for conserving forest carnivores, American marten, fisher, lynx, and wolverine in the western United States. General Technical Report RM-254. Fort Collins (CO): USDA Forest Service. Rocky Mountain Forest and Range Experimental Station. p. 38-73.

Pritchard JK, Wen W. 2003. Documentation for STRUCTURE software: version 23. Chicago, IL: University of Chicago. [Updated 2010 Feb 2; cited 2010 June 27]. Accessed from: http://pritch.bsd.uchicago.edu.

Raine RM. 1983. Winter habitat use and responses of snow to fisher (Martes pennanti) and marten (Martes americana) in southeastern Manitoba. Can J Zool. 61:25-34.

Raymond M, Rousset F. 1995. GENEPOP (version 3.4): population genetics software for exact tests and ecumenicism. J Hered. 86:248-249.

Rice WR. 1989. Analyzing tables of statistical tests. Evolution. 43:223-225.

Roy KD. 1991. Ecology of reintroduced fishers in the Cabinet Mountains of Montana. Missoula (MT): University of Montana 94 p.

Smouse PE, Long JC, Sokal RR. 1986. Multiple regression and correlation extension of the Mantel test of matrix correspondence. Syst Zool. 35:627-632.

Trombulak SC, Royar KJ. 2001. Restoring the wild: species recovery and reintroduction. In: McGrory Klyza C, editor. Rewilding the Northeast: A New Wilderness Paradigm. Hanover (Germany): University Press of New England. p. 157-181.

Wallace K, Henry R. 1985. Return of a Catskill native. NY State Conservationist. 40:16-19.

Weir BS, Cockerham CC. 1984. Estimating F-statistics for the analysis of population structure. Evolution. 38:1358-1370.

Williams BW, Scribner KT. 2010. Effects of multiple founder populations on spatial genetic structure of reintroduced American martens. Mol Ecol. 19:227-240.

Williams RN, Rhodes OE Jr., Serfass TL. 2000. Assessment of genetic variance among source and reintroduced fisher populations. J Mammal. 81:895-907.

Wilson GA, Rannala B. 2003. Bayesian inference of recent migration rates using multilocus genotypes. Genetics. 163:1177-1191.

Wisely SM, Buskirk SW, Russell GA, Aubry KB, Zielinski WJ. 2004. Genetic diversity and structure of the fisher (Martes pennanti) in a peninsular and peripheral metapopulation. J Mammal. 85:640-648.

York EC. 1996. Fisher population dynamics in northcentral Massachusetts [PhD dissertation]. Amherst (MA): University of Massachusetts.

Received June 17, 2010; Revised January 7, 2011; Accepted January 9, 2011

Corresponding Editor: C Scott Baker 